\title{
Gargle, Tablet for Solution Dosage Form
}

National Cancer Institute

\section{Source}

National Cancer Institute. Gargle, Tablet for Solution Dosage Form. NCI Thesaurus. Code C149520.

Solid preparation consisting of a tablet intended to be dissolved in water to obtain a gargle. 